\title{
Fractional Order Sliding Mode Controller Fed Load-Frequency Control of Multi-Area Deregulated Power System Network
}

\author{
K. Vimala Kumar, V. Ganesh
}

\begin{abstract}
This paper presents a Fractional Order Sliding Mode Controller (FOSMC) for load frequency control of multi area power system in deregulated environment. In deregulated power system the design of controller is more complicated due to contracted and un-contracted load demands. This proposed controller shall take care of system nonlinearities and uncertainties under bilateral contract scenario for sudden load disturbances. The performance of proposed controller compared to PI controller and without any controller.
\end{abstract}

Keywords: Load Frequency Control, Multi-Area Deregulated Power System, Fractional Order Sliding Mode Controller, PI Controller

\section{INTRODUCTION}

In power system frequency is one of the parameters for healthy operation under sudden load disturbances [1].The machine, load increases machine give up kinetic energy to the load, load decreases machine barrow kinetic energy [2]. In conventional power system design of load frequency controller is easier and insensitive to tie line power flow [3]. In deregulated power system design of controller is sensitive to tie line power flow [3]. In [4], presented ACS algorithm tuned with ANFIS trained with online data. A FOPID controller presented and investigations reveals that the performance of FOPID controller better than IO controller [5]. A DE optimized [6] fuzzy PID controller presented for restructured power system connected with AC/DC line. A coordinated control [7] strategy of TCPS-SMES presented with penetration of DFIG for LFC. A SPHBMO tuned FLC-PID controller presented for LFC [8].A H-infinity controller [9] presented for restructured power system connected with HVDC link and performance compared to OSMC under various operating conditions and larger load demands. A Fuzzy PID controller with derivative filter optimized by FA presented UPFC and SMEC [10].

A nonlinear SMC [11] presented with matched and unmatched uncertainties for LFC and performance compared

Revised Manuscript Received on February 05, 2020.

* Correspondence Author

K. Vimala Kumar*, Ph.D Scholar, JNTUA, Ananthpur Andhra Pradesh, India. E-mail:princevimal81@gmail.com

V. Ganesh, Professor, JNTUP, Pulivendula, Andhra Pradesh, India. E-mail:ganivg@gmail.com

(C) The Authors. Published by Blue Eyes Intelligence Engineering and Sciences Publication (BEIESP). This is an open access article under the CC BY-NC-ND license (http://creativecommons.org/licenses/by-nc-nd/4.0/) change in frequency varies with kinetic energy stored in the

to linear SMC, through simulation results the dynamic parameters such as overshoot and settling time reduced by 30 percent. A QOHS [12] presented for AGC of multi area power system in coordination with TCSC. In [13], CS optimized 2DOF-IDD controller demonstrated with different FACTS devices on multi area LFC. A hGSA-PS suggested for LFC of restructured power system and superiority of the controller compared to FA,DE and BFOA [14]. A hybrid FA-PS Fuzzy PID controller [15] presented and performance compared to DE, CPSO. An ACS algorithm based controller for simultaneous control of multi area power system interconnected with AC Tie line parallel with DC link[16].A type-2 FLC presented with error feedback learning proposed[17].

A DMPC presented [18] for multi area deregulated power system by considering bilateral contacts. A [19] newly developed QOGWO tested on two area LFC and effectiveness of optimization algorithm compared to intelligent controllers. In [20] integral controller tuned with ICA algorithm and effectiveness of the ICA tested with SSSC and CES to enhance the dynamic performance of restructured power system. A hybrid DEPS[21]optimized Fuzzy PID controller presented and effectiveness of the methodology compared to BFOA, GA. The ABC algorithm [22] presented for optimizing gains of PI3D controller and performance compared to EP, GA, GSA and PSO. A QOSOS algorithm presented for effective solution for LFC[23]. A DE optimized fuzzy PID controller with derivative filter tested on multi area deregulated power system [24]. A combination of IPFC, RFB connected in series with tie line presented and a hybrid DEPS and FLC Optimized PID controller presented [25].

An optimized LFC with IPFC and RFB demonstrated [26].The performance of FACTs devices tested on two area power system with CSA optimized 2DOF presented [27].An ACS algorithm tuned with ANFIS tested on multi-source deregulated power system[28].A new FSMC presented proposed for LFC of multi area power system[29]. A FLC tuned with PSO presented for LFC of multi area deregulated power system [30]. A Second Order Sliding Mode Controller presented for LFC of thermal-thermal power system[31]. H-Infinity loop shaping, BFOA tuning of PID[32,33].A FLC gain scheduling based LFC controller, a FFA tuning of PID controller presented[34,35]. Intelligent controllers such as ANN, ANFIS presented for three area hydro-thermal power system [36], [37]. A MOSHA based FLC controller, BBBC tuned several classical controllers presented for LFC of deregulated power system [38], [39]. 


\section{DEREGULATED POWER SYSTEM MODEL}

The modelling of open market multi-source power system presented in [40-41]. In the structure of deregulated power system each area consisting of thermal-hydro combination. The modelling of multi area deregulated power system presented in $[40,41]$.

$$
\begin{gathered}
D P M=\left[\begin{array}{cccc}
c p f_{11} & c p f_{12} & c p f_{13} & c p f_{14} \\
c p f_{21} & c p f_{22} & c p f_{23} & c p f_{24} \\
c p f_{31} & c p f_{32} & c p f_{33} & c p f_{34} \\
c p f_{41} & c p f_{42} & c p f_{43} & c p f_{44}
\end{array}\right] \\
\sum c p f_{i j}=1 \\
\sum_{j=1}^{M} a p f_{i j}=1
\end{gathered}
$$

Where $\mathrm{M}$ represents total number of GENCOs in each area, ACE Participation Factors (APF's)', and the tie-line power flow is a function of Contract Participation Factor (CPF)

$$
\begin{array}{r}
\Delta P_{\text {tie1-2scheduled }}=\sum_{j=1}^{2} \sum_{j=3}^{4} c p f_{i j} \Delta P_{L}-\sum_{j=3}^{4} \sum_{j=1}^{2} c p f_{i j} \\
\Delta P_{\text {tie1-2error }}=\Delta P_{\text {tie1-2scheduled }}-\Delta P_{\text {tie1-2actual }}
\end{array}
$$

(4)

$$
\sum_{j=1}^{M} a p f_{i j}=1
$$

Where $M$ represents total number of GENCOs in each area, Area Control Error (ACE) is a function of tie line power exchange and frequency deviation.

$$
A C E_{i}=B_{i} \Delta f_{\text {ierror }}+\Delta P_{\text {ierror }}
$$

Where $i=1,2$

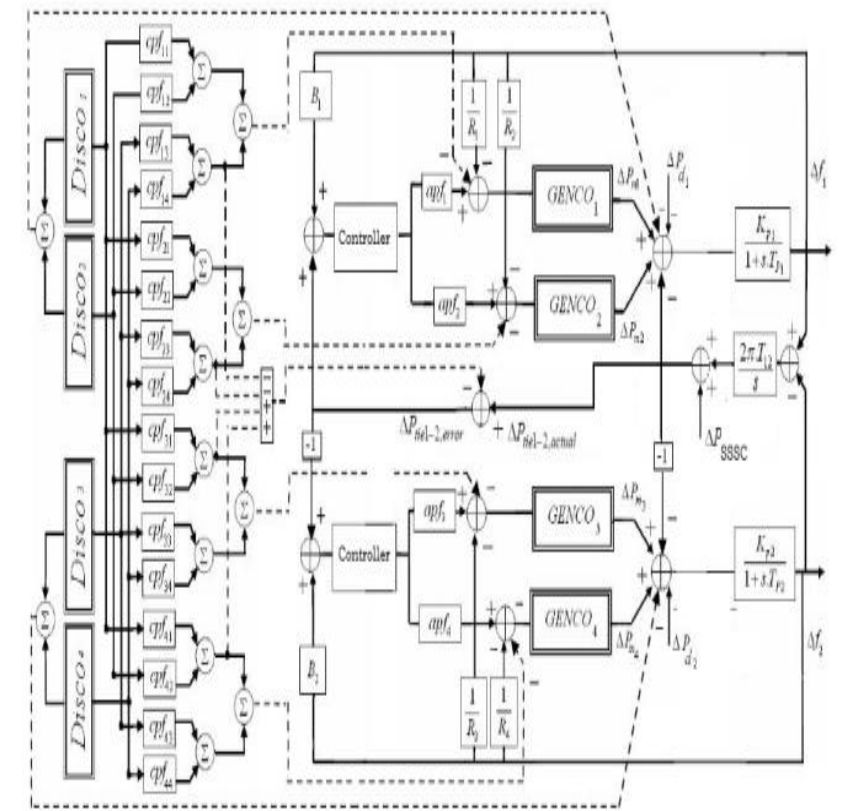

Fig.1 Two area Thermal-Thermal system with AC tie-line in deregulated environment

\section{FRACTIONAL ORDER SLIDING MODE CONTROLLER IMPLEMNTATION FOR LFC}

\section{A. Theory of Fractional Order Calculus for Design \&} Implementation of FOSMC

Fractional Order calculus based Fractional (non-integer) order sliding mode controller designed and implemented for different applications but in this paper FOSMC controller implemented for thermal-thermal multi area deregulated power system for load frequency control.

The non-integer order (Fractional Order) operator $a^{D_{t}^{\alpha}}$ are represented as

$$
a^{D_{t}^{\alpha}} \begin{cases}\frac{d^{\alpha}}{d t^{\alpha}} & \text { for } \alpha>0 \\ 1 & \text { for } \alpha=0 \\ \int_{a}^{t}(d \tau)^{\alpha} & \text { for } \alpha<0\end{cases}
$$

The fractional order derivative originated as defined by R-L[ ]

$$
a^{D_{t}^{\alpha}} f(t)=\frac{1}{\Gamma(m-\alpha)}\left(\frac{d}{d t}\right)^{m} \int_{a}^{t} \frac{f(\tau)}{(t-\tau)^{1-(m-\alpha)}} d \tau
$$

The Laplace transform of fractional derivative as referred by R-L

$$
\left\{0^{D_{t}^{\alpha}} f(t) ; s\right\}=s^{\alpha} F(s)-\sum_{k=0}^{(m-1)} s^{k}\left[o_{t}^{D_{t}^{(\alpha-k-1)}} f(t)\right]_{t=0}
$$

Laplace transform of fractional order derivative under initial condition

$$
G(s)=s^{\alpha} \quad \alpha \in R
$$

The fractional Order derivative obtained in terms of filter response

$$
\widehat{G}(s)=K \prod_{k=-N}^{N} \frac{s+\omega_{k}^{\prime}}{s+\omega_{k}}
$$

The poles and zeros are established by the

$w_{k}^{\prime}=w_{b}\left(w_{h} / w_{b}\right)^{(k+N+0.5(1-\alpha)) /(2 N+1)}$

$$
w_{k}=\omega_{b .}\left(\omega_{h} / \omega_{b}\right)^{(k+N+0.5(1+\alpha)) /(2 N+1)}
$$

$2 \mathrm{~N}+1$ is the order of filter and $w_{b}, \omega_{h}$ are the lower and higher cut-off frequencies

$$
K=w_{h}^{\alpha}
$$

Fractional Order derivative and integral is linear operator as given in equation (14), (15)

$$
\begin{array}{r}
a^{D_{t}^{\alpha}}(f(t)+g(t))=a^{D_{t}^{\alpha}} f(t)+a^{D_{t}^{\alpha}} g(t) \\
a^{D_{t}^{-\alpha}}(f(t)+g(t))=a^{D_{t}^{-\alpha}} f(t)+a^{D_{t}^{-\alpha}} g(t)
\end{array}
$$

\section{B. Implementation of FOSMC for LFC of Multi-Area Power System in Deregulated Environment}

The FOSMC controller implemented for LFC of thermal-thermal DMAPS. In the implementation of FOSMC control law, initially a fractional order Oustaloup filter designed and derivative applied to the output of the filter then derivative output of filter feed it to the signm function. In the implementation of control law for two area deregulated power system depicted in block diagram as shown in Fig.3

$e_{i}=A C E_{i}=B_{i} \Delta f_{\text {ierror }}+\Delta P_{\text {ierror }}, i=1,2$,

The switching function of $i^{t h}$ control area

$$
S_{i}=k_{p} e_{i}+k_{d} D^{-\lambda} e_{i}
$$


The derivative of switching function

$$
\begin{array}{r}
S_{i}=k_{p} e_{i}+k_{d} D^{1-\lambda} e_{i} \\
S_{i}=k_{p} \dot{x}_{\imath}+k_{d} D^{1-\lambda} x_{i}
\end{array}
$$

$$
\begin{gathered}
k_{p} \dot{x}_{\imath}+k_{d} D^{1-\lambda} x_{i}=0 \\
\dot{x}_{l}=x_{i+1}
\end{gathered}
$$

$$
\operatorname{Sgn}(s)=\left\{\begin{array}{c}
-1 \text { if } s<0 ; \\
1 \text { if } s>0 ;
\end{array}\right.
$$

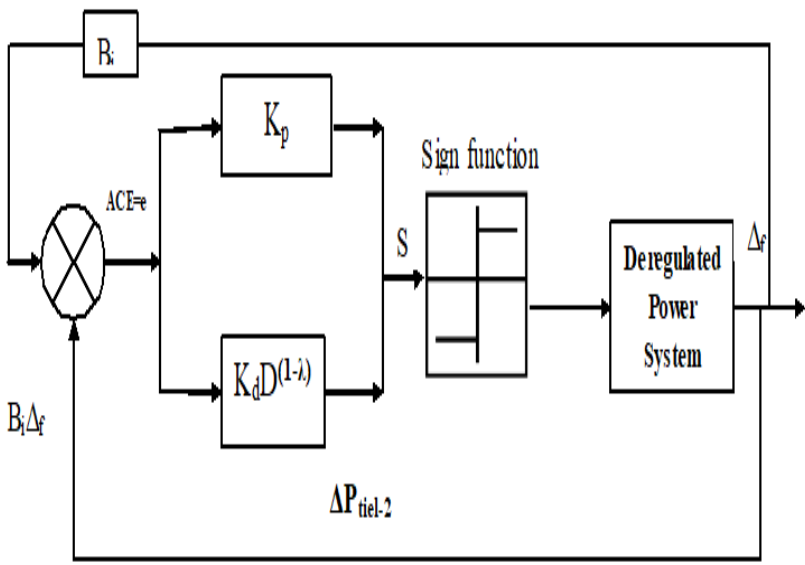

Fig.2 Functional Diagram of FOSMC for Open-Market Power System

\section{SIMULATION RESULTS}

Under bilateral lateral transaction scenario simulations are performed and consider that DISCOMs draw a power of 0.1 p.u MW.

The contribution of each GENCO of each control area $a p f 1=0.6, a p f 2=1-a p f 1=0.4$

$\operatorname{apf} 3=0.6$, apf $4=1-\operatorname{apf} 3=0.4$

A. Thermal Multi-Source Power System in Open-Market Environment with Bilateral Transactions The DPM matrix for simulation studies

$$
\begin{gathered}
\mathrm{DPM}=\left[\begin{array}{cccc}
0.5 & 0.3 & 0.1 & 0.3 \\
0.1 & 0.2 & 0.6 & 0.2 \\
0.4 & 0.0 & 0.2 & 0.1 \\
0.0 & 0.5 & 0.1 & 0.4
\end{array}\right] \\
\Delta P_{m i}=\sum_{i}^{j} c p f_{i j} \Delta P_{L j} \\
\Delta \mathrm{P}_{\mathrm{m} 1}=0.5(0.1)+0.3(0.1)+0.1(0.1)+0.3(0.1)=0.12 \mathrm{pu} \\
\mathrm{MW} ; \\
\Delta \mathrm{P}_{\mathrm{m} 2}=0.11 \mathrm{pu} \mathrm{MW} \\
\Delta P_{m 3}=0.07 \text { pu MW; } \\
\Delta P_{m 4}=0.1 \mathrm{pu} \mathrm{MW;}
\end{gathered}
$$

The frequency response with different controllers indicated with different controllers indicated below

\begin{tabular}{|l|l|}
\hline Name of the Controller & Type of line indicated \\
\hline without controller & Doted lines with circles \\
\hline PI controller & Dotted line \\
\hline FOPI controller & Thick black line \\
\hline FOSMC controller & Thick Red line \\
\hline
\end{tabular}

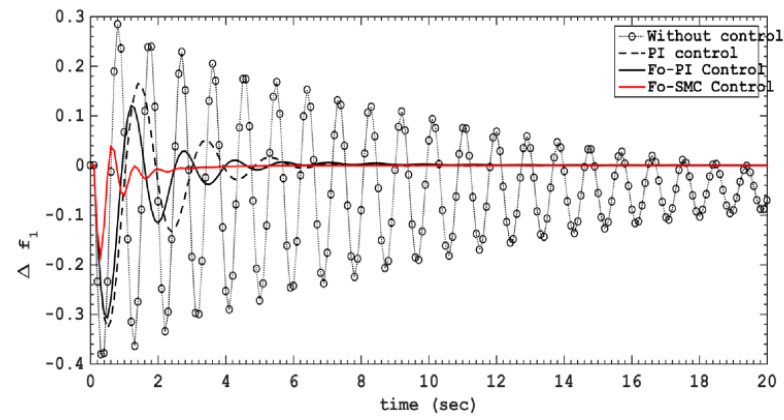

Fig.4 Frequency deviation of Control Area -1

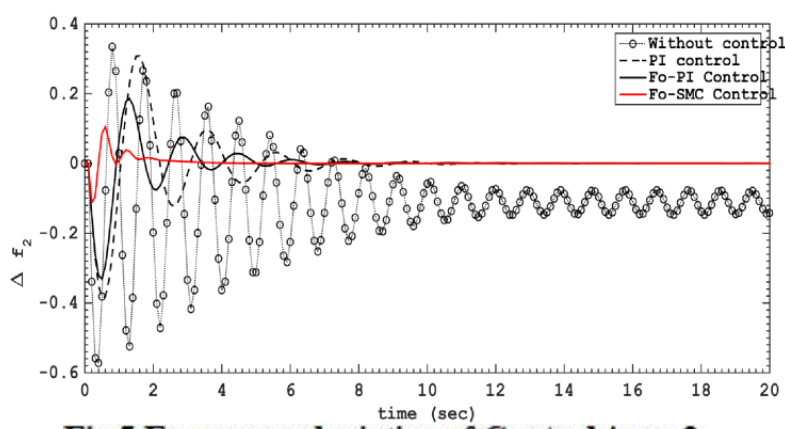

Fig.5 Frequency deviation of Control Area-2

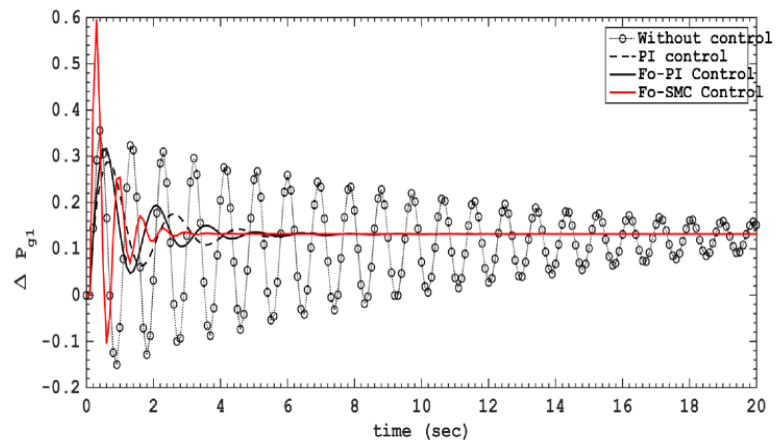

Fig.6 GENCO-1 power output

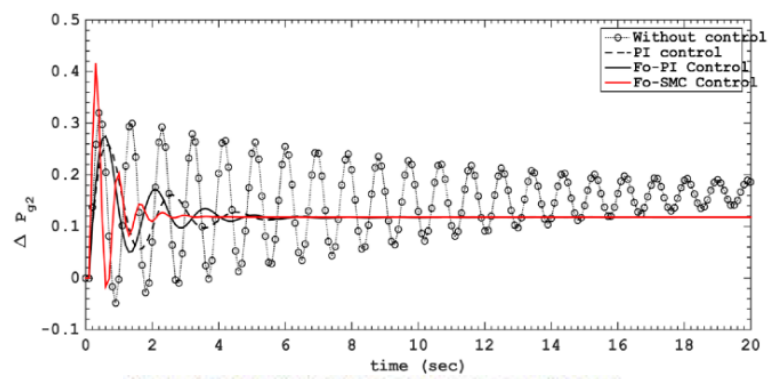

Fig.7 GENCO-2 power output 


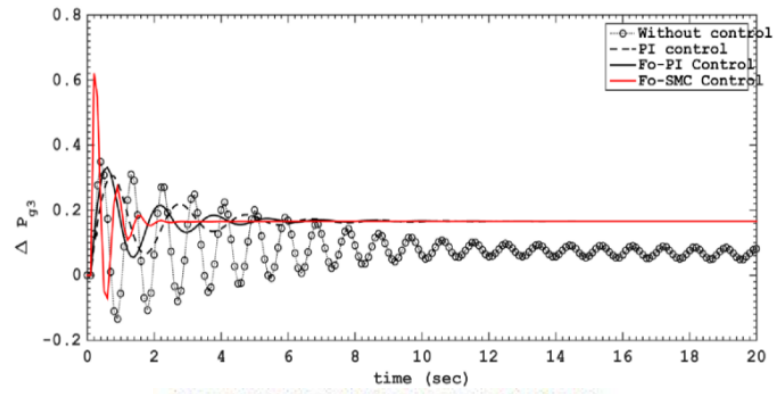

Fig. 8 GENCO-3 Power Output

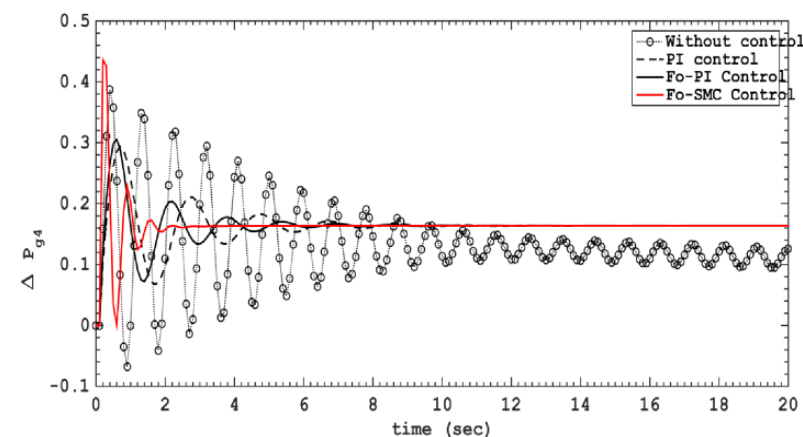

Fig.9 GENCO-4 Power Output, FOSMC controller

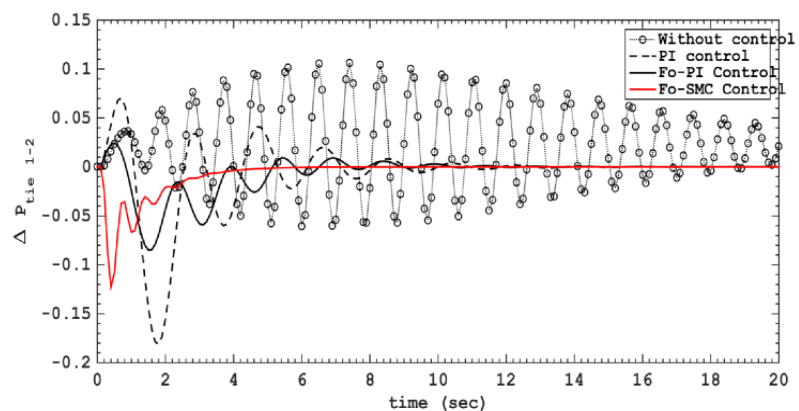

Fig.10 Deviation in Tie line power flow

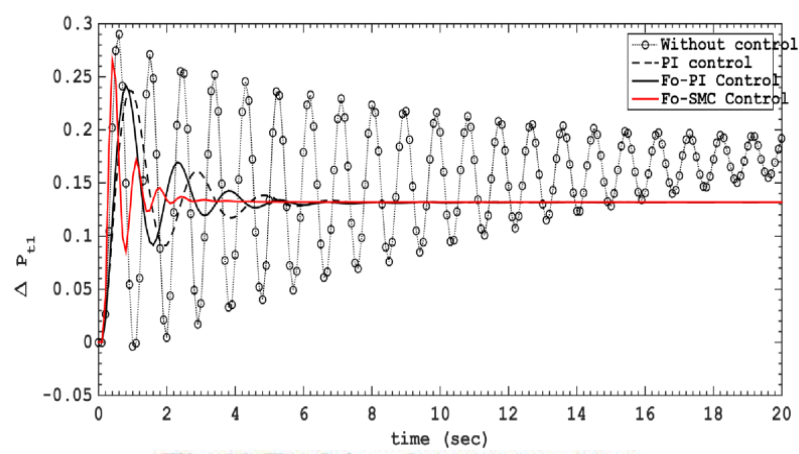

Fig.11 Turbine-1 power output

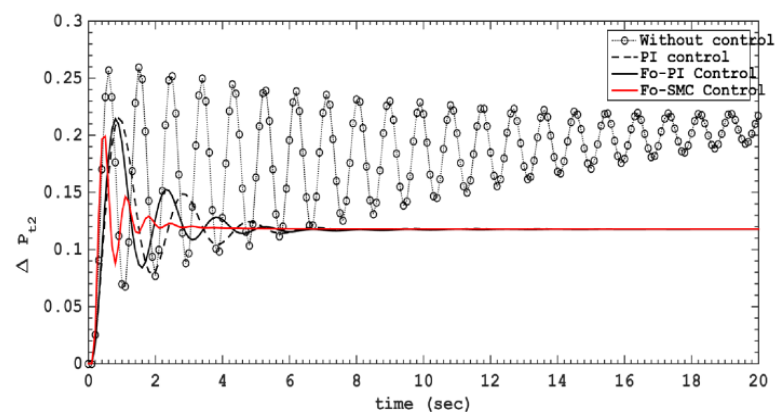

Fig.12:Turbine-2 Power Output

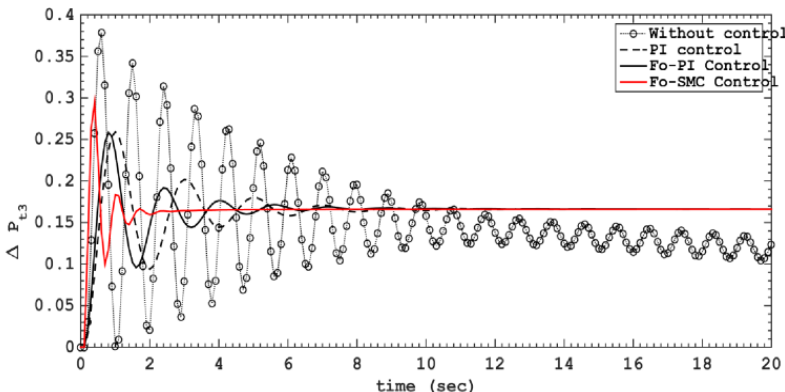

Fig.13 Turbine-3 Power Output

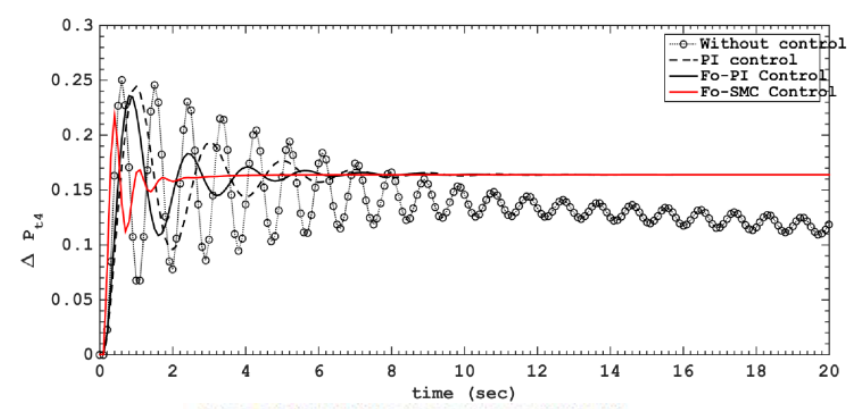

Fig.14 Turbine-4 Power Output

Table.1 Assessment of dynamic parameters of Thermal-Thermal Power System

\begin{tabular}{|c|c|c|c|c|}
\hline $\begin{array}{c}\text { Name of } \\
\text { the } \\
\text { controller }\end{array}$ & $\begin{array}{c}\text { frequency deviation } \\
\text { of Control Area-1 } \\
\text { (\%Peak overshoot) }\end{array}$ & $\begin{array}{c}\text { frequency deviation } \\
\text { of Control Area-2 } \\
\text { (\%Peakovershoot) }\end{array}$ & $\begin{array}{c}\text { Settling } \\
\text { Time of } \\
\text { frequency } \\
\text { deviation in } \\
\text { Control } \\
\text { Area-1 }\end{array}$ & $\begin{array}{c}\text { Settling } \\
\text { Time of } \\
\text { frequency } \\
\text { deviation in } \\
\text { Control } \\
\text { Area-2 }\end{array}$ \\
\hline $\begin{array}{c}\text { Without any } \\
\text { controller }\end{array}$ & $30 \%$ & $36 \%$ & $>20 \mathrm{Sec}$ & $>20 \mathrm{Sec}$ \\
\hline $\begin{array}{c}\text { With PI } \\
\text { Controller }\end{array}$ & $18 \%$ & $33 \%$ & $12 \mathrm{Sec}$ & $14 \mathrm{Sec}$ \\
\hline $\begin{array}{c}\text { With FOPI } \\
\text { Controller }\end{array}$ & $11 \%$ & $19 \%$ & $6 \mathrm{Sec}$ & $8 \mathrm{Sec}$ \\
\hline $\begin{array}{c}\text { With } \\
\text { FOSMC } \\
\text { Controller }\end{array}$ & $3 \%$ & $\mathbf{1 0} \%$ & $\mathbf{3 ~ S e c}$ & $\mathbf{2 . 5} \mathrm{Sec}$ \\
\hline
\end{tabular}

\section{CONCLUSION}

A FOSMC presented for LFC of open market power system. The FOSMC tested on two area thermal-thermal power system for load frequency control by considering DPM matrix of mutual transaction scenario. The new FOSMC reduces peak deviations effectively and response time of the controller is less to mitigate frequency deviations effectively compared to FOPI controller. The proposed work can be extended with fractional order observer controllers as a future scope of work to attain good frequency response of the system.

\section{APPENDIX}

Table.2 GENCO parameters

\begin{tabular}{|c|c|c|c|c|}
\hline \multirow{2}{*}{$\begin{array}{c}\text { GENCOs } \\
\text { parameters }\end{array}$} & \multicolumn{2}{|c|}{ Area1 } & \multicolumn{2}{c|}{ Area2 } \\
\cline { 2 - 5 } & Genco-1 & Genco-2 & Genco-3 & Genco-4 \\
\hline $\mathrm{T}_{\mathrm{T}}(\mathrm{S})$ & 0.32 & 0.30 & 0.03 & 0.32 \\
\hline $\mathrm{T}_{\mathrm{g}}(\mathrm{s})$ & 0.06 & 0.08 & 0.06 & 0.07 \\
\hline $\mathrm{R}(\mathrm{Hz} / \mathrm{pu})$ & 2.4 & 2.5 & 2.5 & 2.7 \\
\hline
\end{tabular}


Table.3 Control Area parameters

\begin{tabular}{|l|l|l|}
\hline Control Area Parameters & Area-1 & Area-2 \\
\hline $\mathrm{K}_{\mathrm{p}(\mathrm{pu} H \mathrm{~Hz})}$ & 120 & 120 \\
\hline $\mathrm{T}_{\mathrm{p}}(\mathrm{s})$ & 20 & 25 \\
\hline $\mathrm{B}_{(\mathrm{pu} H z)}$ & 0.425 & 0.396 \\
\hline
\end{tabular}

TABLE-2 \&TABLE-3 ARE CONSIDEREd For SimUlation

\section{REFERENCES}

1. O. I. Elgerd and H. H. Happ, "Electric Energy Systems Theory: An Introduction," in IEEE Transactions on Systems, Man, and Cybernetics, vol. SMC-2, no. 2, pp. 296-297, April 1972.

2. D. P. Kothari., and I. J. Nagrath., "Modern Power System Analysis" 3rd Edition, Tata McGraw-Hill Publishing Company Ltd, 2009

3. Demiroren, A. \& Zeynelgil, H.L. "GA application to optimization of AGC in three-area power system after deregulation", International Journal of Electrical Power \& Energy Systems. 29. 230-240.

4. Selvaraju, Ramesh \& Somaskandan, Ganapathy. ACS algorithm tuned ANFIS-based controller for LFC in deregulated environment.Journal of Applied Research and Technology, pp.152-166.

5. L. C. Saikia and S. Debbarma, "Application of a non-integer order controller in AGC of a two area thermal system under deregulated environment: A preliminary study," International Conference on Sustainable Energy and Intelligent Systems (SEISCON 2011), Chennai, 2011, pp. 390-395.

6. Sahu Rabindra \&Gorripotu, Tulasichandra\& Panda, Sidhartha. DE optimized fuzzy PID controller with derivative filter for LFC of multi source power system in deregulated environment. Ain Shams Engineering Journal, (2015) 6, pp.511-530.

7. P. Bhatt, S. P. Ghoshal, R. Roy "Load frequency control of interconnected restructured power system along with DFIG and coordinated operation of TCPS-SMES,"Joint International Conference on Power Electronics, Drives and Energy Systems \& 2010 Power India, New Delhi, 2010, pp. 1-6.

8. O. Abedinia, M. S. Naderi and A. Ghasemi, "Robust LFC in deregulated environment: Fuzzy PID using HBMO," 10th International Conference on Environment and Electrical Engineering, Rome, 2011, pp. 1-4.

9. T. A. Kumar, G. Venu and N. V. Ramana, "Load frequency control of multi area power system in deregulated environment with robust Controllers in coordination with frequency controllable HVDC link,"International Conference on Energy Efficient Technologies for Sustainability (ICEETS), Nagercoil, 2016, pp. 473-478.

10. Pradhan, Pratap \& Sahu, Rabindra \& Panda, Sidhartha,"Firefly algorithm optimized fuzzy PID controller for AGC of multi-area multi-source power systems with UPFC and SMES", Engineering Science and Technology, an International Journal, 19 (2016), pp. 338-354

11. Prasad, S., Purwar, S., Kishor, N.: 'Non-linear sliding mode load frequency control in multi-area power system', Control Eng. Pract., 2017, 61, pp. 81-92.

12. M. Nandi, C. K. Shiva, V. Mukherjee, "TCSC based automatic generation control of deregulated power system using quasi-oppositional harmony search algorithm", Eng. Sci. Technol. Int. J., vol. 20, pp. 1380-1395, Aug. 2017.

13. P. Dash, L.C. Saikia, N. Sinha, Comparison of performances of several FACTS devices using Cuckoo search algorithm optimized 2DOF controllers in multi-area AGC Int J Electr Power Energy Syst, 65 (2015), pp. 316-324

14. Sahu, R.K., Panda, S., Padhan, S.: 'A novel hybrid gravitational search and pattern search algorithm for load frequency control of nonlinear power system', Appl. Soft Comput., 2015, 29, pp. 310-327

15. Sahu, R.K., Panda, S., Pradhan, P.C.: 'Design and analysis of hybrid firefly algorithm-pattern search based fuzzy PID controller for LFC of multi area power systems', Electr. Power Energy Syst., 2015, 69, pp. 200-212.

16. M. Ma, C. Zhang, X. Liu and H. Chen, "Distributed Model Predictive Load Frequency Control of the Multi-Area Power System After Deregulation," in IEEE Transactions on Industrial Electronics, vol. 64, no. 6, pp. 5129-5139, June 2017.

17. Guha, D., Roy, P.K., Banerjee, S.'Load frequency control of large power system using quasi-oppositional grey wolf optimization algorithm', Int. J. Eng. Sci. Technol., 2016, 19, (4), pp. 1693-1713.

18. M. Ponnusamy, B. Banakara, S. S. Dash, M. Veerasamy, "Design of integral controller for Load Frequency Control of Static Synchronous

Series Compensator and Capacitive Energy Source based multi area system consisting of diverse sources of generation employing Imperialistic Competition Algorithm", International Journal of Electrical Power \& Energy Systems, vol. 73, pp. 863-871, 2015.

19. Sahu, R.K., Gorripotu, T.S., Panda, S.: 'A hybrid DE-PS algorithm for load frequency control under deregulated power system with UPFC and RFB', Ain Shams Eng. J., 2015, 6, pp. 893-911.

20. Naidu, K., H. Mokhlis, A. H. A. Bakar, and V. Terzija."Performance Investigation of ABC Algorithm in Multi-Area Power System with Multiple Interconnected Generators.” Applied Soft Computing 57: 436-451, 2017.

21. Guha, D., Roy. P. Banerjee, S.Quasi-oppositional differential search algorithm applied to load frequency control. Engineering Science and Technology: An International Journal, 19, 1635-1654, 2016.

22. Hassan Haes Alhelou,Mohamad-Esmail Hamedani-Golshan, Reza Zamani , Ehsan Heydarian-Forushani and Pierluigi Siano "Challenges and Opportunities of Load Frequency Control in Conventional, Modern and Future Smart Power Systems: A Comprehensive Review ",Energies 2018, 11, 2497; doi:10.3390/en11102497.

23. Saroj Padhan, Rabindra Kumar Sahu \&Sidhartha Panda, "Application of Firefly Algorithm for Load Frequency Control of Multi-area Interconnected Power System", Pages 1419-1430, Published online: 09 Sep 2014.

24. Chidambaram, I.; Paramasivam, B. Optimized load-frequency simulation in restructured power system with redox flow batteries and interline power flow controller. Int. J. Electr. Power Energy Syst. 2013, 50, 9-24.

25. P. Dash, L.C. Saikia, N. Sinha, Comparison of performances of several FACTS devices using Cuckoo search algorithm optimized 2DOF controllers in multi-area AGC Int J Electr Power Energy Syst, 65 (2015), pp. 316-324

26. T.Bharath Kumar, M.Uma Vani, "Load Frequency Control in Two Area Power System using ANFIS" , Computer Engineering and Intelligent Systems www.iiste.org, ISSN 2222-1719 (Paper) ISSN 2222-2863 (Online) Vol.5, No.9, 201427

27. A.G. D. Kumar and N. V. Ramana, "A Neuro fuzzy sliding mode controller for load frequency problem in deregulated environment for multi area power system," 2016 IEEE 7th Power India International Conference (PIICON), Bikaner, 2016, pp. 1-6

28. HouGuolian, Qin Lina, Zheng Xinyan and Zhang Jianhua, "Application of PSO-based fuzzy PI controller in multi-area AGC system after deregulation," 7th IEEE Conference on Industrial Electronics and Applications (ICIEA), Singapore, 2012, pp. 1417-1422.

29. K. V. Kumar, T. A. Kumar and V. Ganesh, "Chattering free sliding mode controller for load frequency control of multi area power system in deregulated environment," IEEE 7th Power India International Conference (PIICON), Bikaner, 2016, pp. 1-6

30. A.R. Davidson and S. Ushakumari, "H-infinity loop-shaping controller for load frequency control of an uncertain deregulated power system," 2016 International Conference on Electrical, Electronics, and Optimization Techniques (ICEEOT), Chennai, 2016 pp. 2185-2191

31. Ali, E.; Abd-Elazim, S. BFOA based design of PID controller for two area Load Frequency Control with nonlinearities. Int. J. Electr. Power Energy Syst. 2013, 51, 224-231.

32. Sabahi K, Ghaemi S, Pezeshki S (2014) Application of type-2 fuzzy logic system for load frequency control using feedback error learning approaches. Appl Soft Comput 21, pp.1-11

33. B. Mohanty and P. K. Hota, "Comparative performance analysis of fruit fly optimisation algorithm for multi-area multi-source automatic generation control under deregulated environment," in IET Generation, Transmission \& Distribution, vol. 9, no. 14, pp. 1845-1855, 5112015.

34. A.Demiroren, N. S. Sengor, H. L. Zeynelgil, "Automatic generation control by using ANN technique", Elect. Power Components .Systems., vol. 29, no. 10, pp. 883-896, Oct. 2001.

35. Prakash S, Sinha S (2011) Load frequency control of three area interconnected hydro-thermal reheat power system using artificial intelligence and PI controllers. Int J Eng Sci Technol 4(1), pp.23-37

36. J. Sadeh and E. Rakhshani, "Multi-area load frequency control in a deregulated power system using optimal output feedback method," 5th International Conference on the European Electricity Market, Lisboa, 2008, pp. $1-6$. 
37. E. Rakhshani and J. Sadeh, "Simulation of two-area AGC system in a competitive environment using reduced-order observer method," 5th International Conference on the European Electricity Market, Lisboa, 2008, pp. 1-6.

38. T. Mahto and V. Mukherjee, "Fractional order fuzzy PID controller for wind energy-based hybrid power system using quasi-oppositional harmony search algorithm," in IET Generation, Transmission \& Distribution, vol. 11, no. 13, pp. 3299-3309, 792017.

39. Minh B.L.N., Huynh V.V., Nguyen T.M., Tsai Y.W, "Decentralised adaptive double integral mode controller for multi-area power systems", Math.Probl. Eng. (2018), pp. 1-11

40. A Saha and L.C Saikia, "Renewable energy source-based multiarea AGC system with integration of EV utilizing cascade controller considering time delay".Int. Trans. on Elect.Energy Syst., Vol.29, No.1, pp 2646. 2019

41. N. Kumar, B. Tyagi and V. Kumar, "Multi area automatic generation control using BBBC tuned several classical controllers in deregulated environment," International Conference on Energy Economics and Environment (ICEEE), Noida, 2015, pp. 1-6.

42. O. Abedinia, N. Amjady, A. Ghasemi, and H. Shayeghi, "Multi-stage fuzzy load frequency control based on multiobjective harmony search algorithm in deregulated environment," J. Oper. Autom.Power Eng., vol. 1, pp. 63- 73, 2013.

43. Riccardo caponetto,ciovanniDongola,luigifortuna\&ivopetras, "Fractional Order Systems Modeling and Control Applications. Page No.1- 30.

44. ConcepcionAlicaMonje,YangquanChen,Blas Manue Vinagre,Dingyu Xue\&Vicente Feliu, "Fractional Order Systems And Control Fundamentals and Applications" AIC Springer publication

45. IVO Petras, "Fractional Derivatives, Fractional Integrals and Fractional Differential Equations in Matlab" Technical University of Kosice,Slovak Republic

46. YangQuan Chen, Ivo Petr'a`s and Dingy"uXue" Fractional Order Control - A Tutorial" American Control Conference Hyatt Regency Riverfront, St. Louis, MO, US, June 10-12, 2009.

\section{AUTHOR PROFILE}

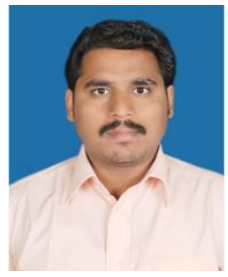

K. Vimala Kumar, received His B. Tech Degree in Electrical \& Electronics Engineering from S.S.N Engineering College Ongole, Andhra Pradesh India in 2002.M.Tech with Electrical Power System From Jawaharlal Nehru Technological University, Hyderabad, India in 2008. He is a research student of Jawaharlal Nehru Technological University, Anantapur, India. Currently, he is working as Assistant Professor in the department of Electrical and Electronics Engineering, J.N.T.U.A College of Engineering, Pulivendula. He is having 15 Years of Teaching Experience. His interested areas are Power System Deregulation, Power System Operation and Control, Power System Design and Dynamic Load Modeling.

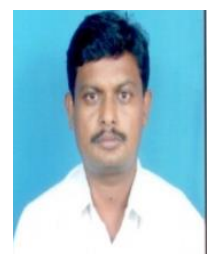

Ganesh Vulasala, is completed B.Tech from JNT University, M.Tech from S.V.University, Tirupathi, India and Ph.D from J.N.T.University Anantapur, Andhra Pradesh, INDIA. He is Presently working as Associate Professor in the Department of Electrical Engineering, J.N.T. University, Anantapur, Andhra Pradesh, India. His areas of interest are Renewable energy sources and its effects to power systems, Smart Grid and its applications, HVDC and Deregulation and Genetic Algorithms and its applications to Electrical distribution systems and its automation. 